

\title{
Key features in the development of unimorph Stainless Steel cantilever with screen-printed PZT dedicated to energy harvesting applications
}

\author{
Maria Isabel Rua Taborda, Catherine Elissalde, U-chan Chung, Mario \\ Maglione, Egon Fernandes, Armaghan Salehian, Onuma Santawitee, Hélène \\ Debéda
}

\section{To cite this version:}

Maria Isabel Rua Taborda, Catherine Elissalde, U-chan Chung, Mario Maglione, Egon Fernandes, et al.. Key features in the development of unimorph Stainless Steel cantilever with screen-printed PZT dedicated to energy harvesting applications. International Journal of Applied Ceramic Technology, 2020, 17 (6), pp.2533-2544. 10.1111/ijac.13588 . hal-02898843

\section{HAL Id: hal-02898843 https://hal.science/hal-02898843}

Submitted on 5 Oct 2020

HAL is a multi-disciplinary open access archive for the deposit and dissemination of scientific research documents, whether they are published or not. The documents may come from teaching and research institutions in France or abroad, or from public or private research centers.
L'archive ouverte pluridisciplinaire HAL, est destinée au dépôt et à la diffusion de documents scientifiques de niveau recherche, publiés ou non, émanant des établissements d'enseignement et de recherche français ou étrangers, des laboratoires publics ou privés. 


\title{
Key features in the development of unimorph Stainless Steel cantilever with screen-printed PZT dedicated to energy harvesting applications
}

\author{
Maria Isabel Rua Taborda ${ }^{1,2}$, Catherine Elissalde ${ }^{2}$, U-Chan Chung ${ }^{2}$, Mario Maglione ${ }^{2}$, \\ Egon Fernandes $^{3}$, Armaghan Salehian ${ }^{3}$, Onuma Santawitee ${ }^{1}$, Hélène Debéda ${ }^{1, *}$.
}

\author{
${ }^{1}$ University of Bordeaux, IMS Laboratory, UMR 5218, F-33405 Talence, France. \\ ${ }^{2}$ CNRS, University of Bordeaux, ICMCB Laboratory, UMR 5026, 87 avenue du Dr A. Schweitzer, \\ 33608 Pessac, France. \\ ${ }^{3}$ University of Waterloo, Energy Harvesting and Vibrations Lab, Mechanical and Mechatronics \\ Engineering, Waterloo, Waterloo, ON, N2L 3G1, Canada
}

*Corresponding author e-mail: helene.debeda@ims-bordeaux.fr

\begin{abstract}
:
The design and processing of vibrational energy harvester based on screen-printed piezoelectric lead zirconate titanate $(\mathrm{Pb}($ ZrxTi1-x)O3 (PZT)) are here described. Two different structures, a simple cantilever and a complex zig-zag geometry made of PZT layer sandwiched between gold electrodes and supported on a metallic stainless steel substrate have been successfully fabricated by screen printing thick film technique. Compared to bulk PZT ceramics, the main limiting features at different scales are porosity, interfaces and bending issues. The microstructural analysis of the interfaces in the cantilever has highlighted the formation of an interface between the substrate and the bottom electrode which ensures cohesion of the structure but can limit its dynamic. Bending has shown to be dependent on the thickness of the active piezoelectric layer. Dielectric and electromechanical characterizations performed on multilayers, bulk ceramics, and freestanding screen-printed disks are compared and discussed on the basis of interface issues.
\end{abstract}

Keywords: PZT, thick film, piezoelectric, energy harvester, stainless steel substrate, interfaces. 


\section{Introduction}

Due to its high electromechanical coupling coefficient ( 50\% [1]) $\mathrm{Pb}\left(\mathrm{Zr}_{\mathrm{x}} \mathrm{Ti}_{1-\mathrm{x}}\right) \mathrm{O}_{3}(\mathrm{PZT})$ remains preferentially used as actuators, transducers or sensors in a massive industry production Although the hazardous lead content remains a significant drawback, PZT is also an attractive material for micro-scale energy harvesting applications [2][3][4]. Piezoelectric vibration EH based on polymers (PVDF, polyamides or parylene $\mathrm{C}$ ) and lead-free materials $(\mathrm{AlN}, \mathrm{ZnO})$ are also investigated in the literature but the first ones present serious lifetime and aging issues and the second ones suffer from moderate piezoelectric coupling factors $[5][6][7][8][9][10]$. Many designs of piezoelectric vibration EH use a cantilever as the mechanical converter. This simple cantilever structure consists of a supporting body (passive substrate), a piezoelectric layer as the active material and a proof mass for both tuning the resonance frequency and increasing strain in the active material. Thin piezoelectric films $(<1 \mu \mathrm{m})$ are less suitable when large power density is required due to their weak electromechanical coupling. Vibration EH based on screen-printed piezoelectric thick films ( 1 to $100 \mu \mathrm{m}$ ) lead to better energy densities than thin layers and overcome the assembly issues inherent to bulk ceramics [11]. Early studies devoted to vibration EH using piezoelectric thick or thin films are mostly based on silicon [2][4][12][13]. Although high normalized power densities are obtained, their brittleness makes them unfeasible to exploit ubiquitous ambient vibrations. Thus, metal-based substrates have received significant interest, especially stainless steel substrates over silicon ones, due to better mechanical strength, a lower Young's Modulus and the possibility to be pre-stressed in order to avoid tensile cracks of ceramic piezoelectric materials [3][14-21].

Recently, PZT layers supported on metallic substrates and its interface circuitry were developed, in order to collect and regulate the energy for smart grid applications [22][23]. Power output tests results were presented, showing an improved performance compared to other MEMS-based piezo-electromagnetic devices. By integrating a screen-printed PZT layer sandwiched between two gold electrodes and supported on a stainless steel substrate (SS), vibrations resulting from the induced magnetic force led to harvested power. Moreover the novel design of the printed MEMS device, consisting in a centrally-supported modified zig-zag geometry has allowed decreasing the characteristic high resonance frequencies of MEMS structures and maintaining high strains, with a dissipation of approximately $9 \mu \mathrm{W}$ across a $1 \mathrm{M} \Omega$ load, and a low fundamental frequency of $60 \mathrm{~Hz}$, matching the fundamental frequency of the American power grid. 
However, energy harvesting performance depends on a large extent on the microstructure, the properties of the active piezoelectric material and the quality of the interfaces [16][18][24][25], parameters inherently dependent on the fabrication process of the device. In particular, correct densification step of the PZT layer is required to limit the detrimental effect of porosity (leakage current) and to ensure high piezoelectric properties. Another issue to consider is the mechanical clamping effect arising from the substrate [21][24]. The quality of the interfaces between the different layers can be profoundly affected by the residual thermal stresses resulting from the mismatch of thermal expansion coefficients between the materials constituting the structure, leading to potential cracks in the active layer and bending of the structure [26][27]. Here, investigation of different PZT based EH is reported, focusing on interfaces, microstructure, and highlighting key guidelines for screen-printed EH processing. First, the complete EH structure with zig-zag geometry is described, a simple cantilever multilayer structure corresponding to a branch of the zig-zag EH structure is considered, in order to abridge any stainless steel supported cantilever structure. Then screen-printed disks and PZT bulk ceramics are also investigated. Microstructural features, dielectric, piezoelectric properties are compared to highlight the impact of porosity, passive layers, electrodes, and substrate thicknesses on the electromechanical performances of the multilayer energy harvester structure.

\section{Experimental}

\subsection{Electrodes and piezoelectric layers shaping and deposition}

\subsubsection{Multilayer Thick film structures}

The thick film screen-printing technology is selected to fabricate the EH device, as it represents a low-cost and alternative process to classical silicon manufacturing [11]. It requires specific inks, made of powders and organic binder mixed together, that are then transferred onto the substrate through open areas of screen meshes, previously patterned by lithography. The printed films with a thickness in the range 1-100 $\mu \mathrm{m}$ are dried and fired to achieve sintering and ensure adherence of layers. The minimum width and distance between the printed layers is classically $100 \mu \mathrm{m}$. The semi-automatic screen-printer DEK Horizon used for the layers deposition allows alignments at $+/-20 \mu \mathrm{m}$. Compositions and preparation of the commercial or home-made polymer or inorganic pastes used are detailed in the material section. 
The zig-zag EH and simple cantilever structures, both supported on a metallic substrate, and free-standing printed disks are considered.

\subsubsection{Cantilever structures}

The zig-zag EH microsystem consists of a three-dimensional thick-film structure made of the thick PZT film as the active layer, sandwiched between two gold electrodes (Fig. 1 (e)). The layers are supported on a $254 \mu \mathrm{m}$ thick stainless steel (SS) substrate. The software CleWin5 is used to design the electrodes and the piezoelectric layer following the substrate geometry. Short-circuits are avoided using a gap of $200 \mu \mathrm{m}$ between the electrodes layers (Fig. 1 (a)). The layers design (Fig. 1 (b, c, d)) is converted separately into a suitable photo-plotter format, then translated into a patterned thick-film screen using a UV photo sensible polymer film. For the gold electrodes and PZT layers, the screen meshes and the polymer film thicknesses used are 325 mesh - $15 \mu \mathrm{m}$ and 200 mesh - $50 \mu \mathrm{m}$, respectively. The simple cantilever consists in the middle branch of the EH made of the same Au/PZT/Au/SS layers stacking as for the zig-zag (Fig. 1, 2 (e)). The successive layer deposition steps are illustrated in Fig.2. For targeted thicknesses thinner than 40 microns, one layer is directly printed whereas for higher values of thicknesses, snap-off distance is modified and/or two layers are printed

\subsubsection{Printed disks}

Screen-printed disks are made of the same Au electrodes, and PZT printed layers. Once printed, these electroded PZT layers must be ultimately released from the substrate. This is achieved thanks to a sacrificial layer process classically used in MEMS process. The role of this sacrificial layer is to support the active layers during the densification process, without affecting the sintering process and with the minimum interactions with the active layers. Then, either during or after the thermal treatment, the sacrificial layer must be removed to obtain a free-standing active layer [28]. Here, the circular shaping of electroded printed PZT layers is aimed to further conduct piezoelectric characterizations on a simple disk, according to IEEE standards [29]. A sacrificial layer deposition needs to be first deposited on a ceramic substrate prior to the $\mathrm{Au}, \mathrm{PZT}$, and Au layers stacking (Fig. 3). This sacrificial polyester based layer is removed during the sintering process leading to free-standing piezoelectric disks ready for poling process and electrical 
characterizations. The screen chosen for the gold electrodes is the same as the one used for the cantilever fabrication. A $150 \mu \mathrm{m}$ thick stencil is used to achieve thick printed PZT layers in one step. The screen for the sacrificial layer is a $70 \mu \mathrm{m}$ screen mesh with a $50 \mu \mathrm{m}$ thick photosensitive film.

\subsubsection{Ceramics}

The PZT powder is prepared using the same paste formula as for the screen-printing process followed by a drying step at $120^{\circ} \mathrm{C}$ during $8 \mathrm{~h}$. The green pellets (13mm diameter) are uniaxially pressed with a pressure of 18.5 $\pm 2 \mathrm{MPa}$ and then sintered following a firing cycle detailed in section 2.3. Afterward, Au electrodes $(\approx 100 \mathrm{~nm})$ are sputtered on the ceramic disk surfaces for poling and electrical characterization.

\subsection{Materials}

A stainless steel substrate (SS301) with a Young Modulus of 193GPa [22] is selected according to its compatibility with the high firing temperature of the screen-printed layers $\left(900^{\circ} \mathrm{C}\right)$. This substrate is laser cut into the selected geometry. The electrodes and the polyester-based sacrificial layers are printed using commercial pastes from Electroscience Laboratory (ESL), ESL8836 and ESL244T, respectively. The gold paste contains $\sim 64 \mathrm{wt} \%$ of $\mathrm{Au}$ and different oxides such as $\mathrm{SiO} 2, \mathrm{Al} 2 \mathrm{O} 3, \mathrm{CdO}, \mathrm{PbO}$, to ensure the cohesion along with the compacity of the layer and its adherence to the substrate [30]. The PZT paste is prepared with a commercial organic binder from ESL (ESLV400) based on ethylcellulose whose volume percentage is adjusted to obtain a suitable viscosity for printing. The optimal viscosity of the ink has been found with a powder/ organic vehicle ratio (i.e. $85 / 14 \mathrm{wt} . \%$ )

The viscosity of the different inks is controlled with a Brookfield rheometer in order to adapt the viscosity for screen-printing (less than 50 Pas.s for a shear rate of $\left.100 \mathrm{~s}^{-1}\right)$. The $\mathrm{Pb}\left(\mathrm{Zr}_{\mathrm{x}}, \mathrm{Ti}_{1-\mathrm{x}}\right) \mathrm{O}_{3}$ commercial powder (hard navy PZ26 provided by Ferroperm) shows a perovskite-type structure with a predominantly tetragonal phase at room temperature. PZT powder is mixed with three oxides (1\% wt $\mathrm{CuO}, 0.8 \%$ wt $\mathrm{Li}_{2} \mathrm{CO}_{3}$, and $1.2 \% \mathrm{wt} \mathrm{Bi}_{2} \mathrm{O}_{3}$ noted $\mathrm{LBCu}$ ) expected to melt near $600^{\circ} \mathrm{C}$ and then (thus?) improve PZT densification [31]. After a milling step in order to eliminate agglomerates, the grain sizes of $\mathrm{CuO}, \mathrm{Li}_{2} \mathrm{CO}_{3}$ and $\mathrm{Bi}_{2} \mathrm{O}_{3}$ powders are $5 \mu \mathrm{m} \pm 0.03,19 \mu \mathrm{m} \pm 0.11$ and $6 \mu \mathrm{m} \pm 0.03$ respectively. The PZT powder is formed of agglomerates $(\approx 10$ $\mu \mathrm{m})$ made of micrometer or sub-micrometer particles. The as described mixture PZT $+3 \% \mathrm{wt}$ LBCu paste is used to process ceramics, printed disks, and cantilevers. 


\subsection{Thermal treatment and poling step}

After printing, all layers (electrodes, PZT, and sacrificial layer) are dried for $20 \mathrm{~min}$ at $120^{\circ} \mathrm{C}$. A slow drying rate $1^{\circ} \mathrm{C} / \mathrm{min}$ until $120^{\circ} \mathrm{C}$ is preferred for thick layers $(>100 \mu \mathrm{m})$ to avoid cracks. The stacked printed layers are first isostatically pressed $5 \mathrm{~min}$ at $40 \mathrm{MPa}$ and $65^{\circ} \mathrm{C}$ in order to improve the PZT densification [31]. Printed piezoelectric disks and cantilevers, as well as the ceramics, are then sintered 2 hours at $900^{\circ} \mathrm{C}$ using the same firing for the sake of properties comparison (Fig. 4). The heating rate of $1^{\circ} \mathrm{C} / \mathrm{min}$ up to $400^{\circ} \mathrm{C}$ allows a gradual elimination of the organic binder and the elimination of the sacrificial layer (if present). The ramp is then increased to $40^{\circ} \mathrm{C} / \mathrm{min}$ up to $900^{\circ} \mathrm{C}$ for sintering. The $\mathrm{LBCu}$ sintering aid melts at $600^{\circ} \mathrm{C}$. The final PZT thicknesses are approximately $55 \mu \mathrm{m}$ for the cantilevers, $100 \mu \mathrm{m}$ for the disk and 2-3 $\mathrm{mm}$ for ceramics.

Once densified, the samples are polarized. Ag wires of diameter $100 \mu \mathrm{m}$ are glued on the Au electrodes with Ag epoxy paste. Additional ultrasonic wire bonding of $20 \mu \mathrm{m}$ Au wires is led for the zig-zag cantilevers as detailed in previous work [22]. Maximum voltages chosen to avoid dielectric breakdown are respectively of $0.25 \mathrm{kV}, 0.35 \mathrm{kV}$ and $1 \mathrm{kV}$ for cantilevers, disks, and ceramics. This poling step is done under nitrogen and at $280^{\circ} \mathrm{C}$ (a temperature slightly below the Curie temperature), during 10min and voltage is maintained over temperature cooling.

\subsection{Characterizations}

Thickness and roughness profiles are measured with a contact profilometer KLA Tencor-Alpha Step. Particle size distributions of the raw powders are evaluated using laser diffraction spectroscopy from wet dispersions (water) after ultrasound (1 minute) using Malvern Mastersize 2000. Phase structure of the PZT powders and ceramics are identified by X-ray powder diffraction (XRD) using a PANalytical X'Pert MPD diffractometer with $\mathrm{Cu} \mathrm{K} \alpha$ radiation of wavelength $\lambda=1.54056 \AA$. The XRD patterns are recorded at room temperature in the angular range of $2 \theta=8-80^{\circ}$. The microstructures of the samples are observed using a scanning electron microscope (SEM, ZEISS EVO50). Cross polishing (Ilion ${ }^{+}$II 697) at low energy (5keV) is used to prepare proper cross-section surfaces of the EH multilayer for microstructural observations. Fracture surfaces are observed by SEM for ceramics. The SEM images are analyzed using ImageJ to extract 
an apparent porosity defined as the fractional pore area on the cross-sections. Chemical analysis is performed using Energy Dispersive X-ray Spectroscopy (EDX). Thermal dilatometry analyses (DIL Netzsch 402) under Argon and with a heating rate of $2^{\circ} \mathrm{C} / \mathrm{min}$ until $600^{\circ} \mathrm{C}$ (maximum temperature of analyzer) are performed on both PZT ceramic ( $3 \mathrm{~mm}$ thick and $6 \mathrm{~mm}$ diameter) and four piled up discs (1 $\mathrm{mm}$ thick and $9 \mathrm{~mm}$ diameter) of stainless steel (SS301). The dielectric characterizations (permittivity $\varepsilon^{\prime}$, dielectric loss $\tan \delta$ ) are performed in the $100 \mathrm{~Hz}-1 \mathrm{MHz}$ frequency range using an impedance analyzer (HP 4294A) with a home-made temperature controlling system. Impedance measurements are conducted using an Agilent E5061B. The electromechanical and piezoelectric coefficients are then calculated through the resonance and anti-resonance method using the standard IEEE model [29]. 


\section{$3 \quad$ Results and Discussion}

\subsection{Microstructure analysis}

\subsubsection{Densification of PZT}

The microstructures of PZT corresponding to the ceramic, the printed disk, and the simple cantilever are compared (Fig. 5). As mentioned in the experimental section, the PZT is mixed with similar content and nature of organic binder and sintering aid $(3 \% \mathrm{wt} \mathrm{LBCu})$. Whatever the design, the firing profile remains the same for all three structures. Highly densified ceramic is obtained at $900{ }^{\circ} \mathrm{C}$ (relative density $\approx 97 \%$ ) confirming efficient densification at such low temperature thanks to the use of the LBCu sintering aid. SEM images on a fracture surface of the ceramic confirm a low level of apparent porosity and reveal a mean grain size of about $3 \mu \mathrm{m}$ with a narrow grain size distribution (Fig. 5 (a)). The relative density is lower for printed structures (Fig. 5 (b, c)). An estimated apparent porosity of $14 \%$ and $20 \%$ is evaluated, for printed disks and cantilevers respectively. In this case, the grain size distribution is broader, thus a precise estimation of the average grain size cannot be reliable, considering the melted aspect of the grains or agglomerates. In the co-fired printed structures, the sintering shrinkage mismatch between the electrodes and the active PZT layer has to be considered. Differences in shrinkage behavior can generate stresses and defects and lead to constrained sintering compared to free sintering [32][33]. Retardation of PZT sintering kinetics can thus be expected. Moreover, for cantilevers type structures, mechanical clamping from the substrate is an additional parameter that contributes to constrained sintering. The specific preparation for SEM observation of cantilevers can explain the melted aspect of PZT grains (Fig. 5 (b)). In comparison, free surfaces in ceramics allow both more efficient debinding and densification providing a faster kinetic pathway for mass transport and leading to enhanced PZT grain growth. 


\subsubsection{Study of EH structure and interfaces in cantilever structures}

When considering EH cantilevers structures, thermal stresses take place during firing cycle due to the difference of thermal expansion coefficients (CTE) between the different materials constituting the structure. Fig. 6. shows the complete energy harvester after firing with two different PZT layer thicknesses (55 and $100 \mu \mathrm{m}$ ). Bending of the structure is observed for the $100 \mu \mathrm{m}$ final thickness. Indeed, thermal stresses during the firing lead to significant deformation of the structure. This is confirmed by the high difference between the CTE of SS and PZT ceramic highlighted through dilatometry analysis (Fig.7). In the high temperature range $\left(500-600{ }^{\circ} \mathrm{C}\right)$, an average of CTE values of 16.7 and $4.7 \mathrm{ppm} /{ }^{\circ} \mathrm{C}$ are obtained, respectively.

Hsuen et al. have proposed a mathematical solution of the thermal stress in multilayered films on substrates. For this purpose, the system's total strain is decomposed into a uniform bending component [27]. The crosssection of our multilayered system is shown in Fig. 8, where the film layers of individual thicknesses $\left(t_{1 A u}, t_{P Z T}, t_{2 A u}\right)$ are bonded sequentially to the stainless steel (SS) substrate (thickness $\left.t_{s}\right)$. The coordinate system is defined in such a way that the interface between the bottom Au layer (noted $1 A u$ ) and the SS

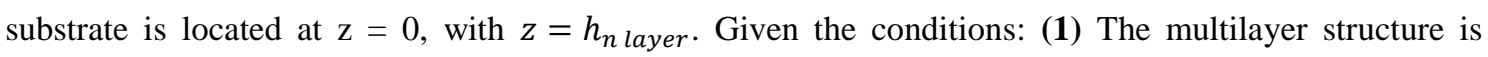
subjected to a temperature change $(\Delta T)$, with residual thermal stresses $(\sigma)$ (eq. 1 and eq. 2 ), (2) the substrate's thickness is much more higher than the one of the active layer $\left(t_{s} \gg t_{P Z T}\right)$, (3) the layers arrangement is asymmetrical and, (4) only the PZT and SS CTE mismatch are considered to contribute to final bending (Au layer effect is overlooked). The curvature $1 / r$ of the structure can be then evaluated using eq. 3.

$$
\begin{gathered}
\sigma_{s}=\frac{E_{s}^{\prime}\left(3 z+2 t_{s}\right)}{3 r}\left(\text { for }-t_{s} \leq z \leq 0\right) \quad(\text { eq. } 1) \\
\sigma_{P Z T}=\frac{E_{s}^{\prime} t_{s}^{2}}{6 t_{P Z T} r}\left(\text { for } t_{s} \gg t_{P Z T}\right)
\end{gathered}
$$




$$
\frac{1}{r}=\frac{6 E_{P Z T}^{\prime} t_{P Z T}\left(\alpha_{P Z T}-\alpha_{S}\right) \Delta T}{E_{s}^{\prime} t_{s}^{2}}=\sum \frac{1}{r_{i}}\left(\text { with } r_{i}=\right.\text { PZT or S) (eq. 3) }
$$

Where $\sigma_{s}$ and $\sigma_{P Z T}$ are the thermal stresses in the substrate and PZT layer, respectively. $E^{\prime}=E /(1-v)$ is the biaxial modulus with $E$ the Young's Modulus and $v$ is the Poisson's ratio of SS substrate or PZT layer individually. $\alpha_{P Z T}$ and $\alpha_{s}$ are the thermal expansion coefficients of the substrate and PZT layer, respectively. $1 / \mathrm{r}$ is the physical representation of the component curvature upcoming from the mismatch between the substrate and the active layer. Using the properties shown in Erreur ! Source du renvoi introuvable., the estimated curvature of the multilayer structure is calculated for different PZT thicknesses, considering a $\Delta T=100^{\circ} \mathrm{C}$.

For a PZT thickness of $100 \mu \mathrm{m}$, an absolute value of $2.69 \mathrm{~mm}$ for the theoretical maximum curvature is obtained with a structure concave facing up whereas the experimental curvature is $3.5 \mathrm{~mm}$ (Fig. 6 (b)). Experimental curvature is evaluated at the highest curvature point containing the PZT active layer of the structure. To validate the trend predicted by the analysis, several cantilevers with different PZT thicknesses have been fabricated $(35,55,60,70,80,100 \mu \mathrm{m})$. The maximum deviation between the experimental and calculated values reaches $29 \%$ for a PZT thickness of $100 \mu \mathrm{m}$ (Fig. 9), this high percentage of error can be explained considering that at higher $t_{P Z T}(80-100 \mu \mathrm{m})$ the condition of the analytical solution $t_{s} \gg t_{P Z T}$ is no longer valid. Decreasing PZT thickness leads indeed to both lower curvature values and a better agreement between experimental and calculated data. Thermal stresses can thus be significantly reduced by adjusting the PZT thickness.

Cantilevers made with PZT thickness lower than $60 \mu \mathrm{m}$ do not show significant bending (around $1 \mathrm{~mm}$ only) (Fig. 6 (c)). The selected PZT thickness is thus $55 \mu \mathrm{m}$.

SEM observations of the cross-section of a non-deformed cantilever $\left(t_{\mathrm{PZT}} \approx 55 \mu \mathrm{m}\right)$ allow to probe the good quality of the interfaces in terms of cohesion and composition (Fig. 10 (a)). Good adhesion of the printed layers is observed between the top gold electrode and the PZT layer without delamination (Fig. 10 (b)). The 
thickness of the top and bottom Au electrodes are 10 and $8 \mu \mathrm{m} \pm 2 \mu \mathrm{m}$, respectively. The top Au electrode roughness $(\approx 300 \mathrm{~nm}$ ) allows smoothing the PZT layer roughness.

The porosity within the active layer is homogeneously distributed without any significant evidence of densification gradients. Tensile stress due to the substrate effect does not seem to hinder densification close to the interface. However, the formation of an interfacial layer of about $20 \mu \mathrm{m}$ between the bottom gold electrode and the SS substrate can be evidenced in Fig. 10 (c). This interfacial layer results from interdiffusion between the substrate and the bottom electrode during the sintering process. Bulk diffusion or diffusion across defect paths (dislocations in the metal, the porosity of gold due to thermal decomposition of organics) can explain the cross-diffusion between the two layers.

EDX analysis of the different layers (Fig. 11) reveals that the interface layer between bottom Au electrode and SS substrate contains $45 \%$ of the elements constituting the gold ink ( $\mathrm{Si}, \mathrm{Pb}, \mathrm{Cu}$ ) and $55 \%$ of elements of the SS substrate ( $\mathrm{Fe}, \mathrm{Cr}$ ). The high level of oxygen confirms the partial oxidation of the substrate in the vicinity of the interface. Furthermore, the PZT layer analysis reveals the presence of $\mathrm{Pb}(68 \mathrm{wt} \%), \mathrm{Zr}$ (21.5wt\%), Ti (8.4wt\%) and $\mathrm{Cu}$ and $\mathrm{Bi}$ from $\mathrm{LBCu}(1.6 \mathrm{wt} \%)$

The interface layer still ensures cohesion between the electrode and the substrate without the presence of Kirkendall porosity that could be more detrimental. However, such diffusion process at the electrode/substrate interface creates a passive layer whose mechanical properties would impact more globally the properties of the device and has to be accurately controlled.

\subsection{Dielectric and electromechanical properties}

Dielectric measurements at different temperatures and frequencies are first carried out on PZT ceramics in order to determine the Curie temperature (Tc) (Fig. 12). The Curie temperature, determined at the maximum of capacitance, occurs at $330^{\circ} \mathrm{C}$ as expected for the PZ26 [34]. Considering measurements performed 24 hours after poling at $0.5 \mathrm{kV} / \mathrm{mm}$, a relative permittivity of 1200 and dielectric losses lower than $0.14 \%$ were measured at room temperature for $1 \mathrm{kHz}$. The permittivity value is slightly lower than the one reported for commercial PZT ceramic $\left(\varepsilon^{\prime} \approx 1300-\right.$ sintering at $\left.1200^{\circ} \mathrm{C}\right)$. Nevertheless, the differences between the two ceramics in terms of grain size and poling conditions $(2-8 \mathrm{kV} / \mathrm{mm}$ for the commercial ceramic) can explain this difference in permittivity values. Dispersion of the permittivity at low frequencies near $T c$ is observed 
but there is no signature of conduction mechanisms activated at high temperature $\left(T>400^{\circ} \mathrm{C}\right)$. However, the increase of $\tan \delta$ from $380^{\circ} \mathrm{C}$ reflects the existence of residual space charges.

Capacitance measurements are also carried out for the printed disk. Relative permittivity close to 600 and dielectric losses $\geq 2.5 \%$ at room temperature and $1 \mathrm{kHz}$ are obtained. Such lower permittivity values compared to PZT ceramics can be partly explained by the lower relative density in the printed disk but cannot be rigorously compared because the applied poling electric field is not the same. However, the level of porosity is also a parameter that determines the maximum value of the field applied during poling.

Impedance measurements are performed for printed disk and simple cantilever (Fig. 13 (a, b)). The obtained resonance frequencies (maximum of $B$ curve) are $f_{r} \approx 416 \mathrm{kHz}$ and $f_{r} \approx 356 \mathrm{kHz}$ for the printed disk and the cantilever, respectively. By using the resonant frequency $f_{r}$ and anti-resonant frequency $f_{a}$, effective electromechanical coupling factor $k_{\text {eff }}$ can be calculated to characterize an arbitrary resonator at any resonance frequency (fundamental or harmonic) thanks to the relation:

$$
k_{e f f}=\sqrt{\frac{\left(f_{a}{ }^{2}-f_{r}{ }^{2}\right)}{f_{a}{ }^{2}}}
$$

Values of $k_{\text {eff }}$ of $26 \%$ and $11 \%$ approximatively are obtained respectively for printed disk and cantilevers, respectively. The lowest $k_{\text {eff }}$ value obtained for the cantilever clearly shows the effect of the passive metallic substrate. Cantilever piezoelectric coefficients have a contribution from $d_{31}$ depending on substrate properties, which cannot be equivalent with the standard IEEE model [29]. The simple conductance measurement is nevertheless relevant as it is directly related to the piezoelectric response of the structure. 
Table 2 reports the material characteristics and summarizes the dielectric and piezoelectric properties of the different PZT based ceramics and printed structures which are compared to a commercial ceramic from Ferroperm. Two examples of PZT layers deposited on metallic substrate investigated in literature are also considered. As expected, the bulk ceramics present the highest dielectric permittivity due to higher density. Compared to the commercial one (sintering at $1200-1300^{\circ} \mathrm{C}$ ), the ceramic sintered in the present work at $900^{\circ} \mathrm{C}$ presents slightly lower permittivity values, but that remains in the same range of the commercial ones despite a significant lower sintering temperature. Lower dielectric properties are also found for printed PZT in comparison with ceramics due to lower densification, as discussed in section 3.1.1. Dielectric losses are also increased in printed layers (by a factor 10).

Electromechanical coupling and piezoelectric coefficients $k_{31}, k p$ and $d_{31}$, are deduced using the standard IEEE model [29]. Disk samples (ceramic or printed one), show comparable values to the commercial ones (table 2), comforting the efficiency of $\mathrm{LBCu}$ to reach high densification at low temperature [35]. For ceramics, even if thin electrodes contribute to higher electromechanical factor, the disk geometry (thicker than for the printed disk) probably introduces errors in the IEEE model. Thinner printed disks are more suitable for the IEEE model and also exhibit high piezoelectric and electromechanical coefficients, despite their lower level of densification and permittivity.

For cantilever structures, lower electromechanical coupling and piezoelectric coefficients are obtained, as confirmed by finite element simulation analysis for the zig-zag cantilever [22]. Overall, lower properties are expected for cantilever multilayer structure due to the presence of the passive metallic substrate supporting the active PZT layers. The substrate induces mechanical clamping stresses that limit the active material densification. Lou-Moeller et al. [24] also confirmed the limitations of the properties of printed PZT (PZ26) thick film when bounded on silicon and alumina substrates. Showing that sintering aids, inherent porosity and mechanical clamping from the substrate, are the main three contributions leading to lower properties values. Furthermore, referring to literature where very dense thin films are also deposited by aerosol on a cantilever SS substrate [16], electromechanical coupling factor $k_{\text {eff }}$ of around 10 are also obtained (table 2). In our case, even if our printed PZT layers present more porosity than the aerosol PZT layers, its higher thickness help to improve the electromechanical coefficient of the multilayer cantilever. More dense and thicker PZT layers clearly improve the performances of the EH as shown in table 2 by the results reported by Colin et $a l$ on thinned bulk PZT glued on both sides of a SS cantilever [21]. With such 
a bimorph configuration and even with a glue interface between the SS substrate and the PZT, an increase of more than a factor of two is obtained thanks to the optimized properties of the thinned bulk ceramic.

Finally, even if the electromechanical coupling coefficient reflects the energy conversion ability and is a relevant criterion to choose the active material, the figure of merit (FOM) (eq.5) should also be considered to compare different materials for energy harvesting applications [7][36]. Reduced permittivity is a way to increase the FOM, despite lower piezoelectric properties. Consequently, the printed structures exhibiting lower permittivity than bulk ceramics could be a good alternative for MEMS piezoelectric energy harvester.

$$
F O M=\frac{d^{2} Y^{2}}{\varepsilon}=\frac{e^{2}}{\varepsilon} \quad \text { (eq. 5) }
$$

\section{Conclusion}

Microstructural characteristics and functional properties of PZT based ceramics, printed disk, and cantilevers have been investigated and compared. Efficient densification of bulk ceramics and printed disks have been obtained at temperatures as low as $900^{\circ} \mathrm{C}$ with the use of $\mathrm{LBCu}$ sintering aid. The optimum permittivity values are obtained for bulk ceramics. Lower densification for cantilever structure is due to the mechanical clamping from the SS substrate that generates constrained sintering. As a result, reduced overall properties have been observed. Nevertheless, the piezoelectric effect has been demonstrated and both effective electromechanical coupling factor and piezoelectric coefficient are comparable to those of literature, confirming the excellent potential of such devices for EH MEMS applications. Compared to bulk ceramics, the main limiting features are the interfaces and bending issues. The microstructural analysis of the interfaces in the cantilever has highlighted the formation of an interphase layer between the substrate and the bottom gold electrode after sintering. This interface is considered as a passive layer that ensures cohesion between the electrode and the substrate, but this could limit the dynamics of the structure under performance. Bending arising from CTE differences between the different materials constituting the cantilever structures have been analytical and experimentally shown to be dependent on the thickness of the active piezoelectric material. Both modeling and experimental approaches have confirmed the possibility to reduce thermal stresses by decreasing the PZT layer thickness. As a result, the two main lines of optimization rely on the improvement of the densification and in better control of the interfaces quality 
(diffusion process, thermal stress). The key parameters to improve dielectric and electromechanical performances in complex ceramic EH structure are the grain size and the composition of the PZT layer, the nature and thickness of electrodes and substrate. The elaboration of bimorphs can also be considered as an additional option to cope with interfaces issues.

\section{Acknowledgments}

The authors would like to thank Dominique Denux (ICMCB - UMR 5026 CNRS-Université Bordeaux) for thermal analysis, Bernard Plano (IMS-UMR5218 CNRS-Université Bordeaux) and Pascale Garreta (Placamat- UMS 3626 CNRS-Université Bordeaux) for the SEM analysis and Xavier Hochart (EXELLIATEMEX) for the pressure step. Part of this work was supported by the grants from the Waterloo Institute of Sustainable Energy.

\section{References}

1. Priya S, Song H-C, Zhou Y, Varghese R, Chopra A, Kim S-G, et al. A Review on Piezoelectric Energy Harvesting: Materials, Methods, and Circuits. Energy Harvest Syst. 2017;4(1):3-39.

2. Lei A, Xu R, Thyssen A, Stoot AC, Christiansen TL, Hansen K, et al. MEMS-based thick film PZT vibrational energy harvester. In: Proceedings of IEEE Int Conf Micro Electro Mech Syst. $2011 ; 125-8$.

3. Nishi T, Ito T, Hida H, Kanno I. Shoe-mounted vibration energy harvester of PZT piezoelectric thin films on metal foils. J Phys Conf Ser. 2016;773(1).

4. Aktakka EE, Peterson RL, Najafi K. Thinned-PZT on SOI process and design optimization for piezoelectric inertial energy harvesting. 16th Int Solid-State Sensors, Actuators Microsystems Conf Beijing. 2011;1649-52.

5. Marin A, Priya S. Multi-mechanism vibration harvester combining inductive and piezoelectric mechanisms. In: Proceedings of SPIE - The International Society for Optical Engineering. 2012.

6. Emamian S, Narakathu BB, Chlaihawi AA, Atashbar MZ. Fabrication and Characterization of Piezoelectric Paper Based Device for Touch and Force Sensing Applications. Procedia Eng. 2016;168:688-91.

7. Elfrink R, Kamel TM, Goedbloed M, Matova S, Hohlfeld D, Van Andel Y, et al. Vibration energy harvesting with aluminum nitride-based piezoelectric devices. $\mathrm{J}$ Micromechanics Microengineering. 2009;19(9). 
8. Hirasawa T, Lin L, Pisano A, Wright P, Yen T. Design and Fabrication of Piezoelectric Aluminum Nitride Corrugated Beam Energy Harvester. In: Power MEMS. 2010. p. 211-4.

9. Wang $\mathrm{P}, \mathrm{Du} \mathrm{H}$. ZnO thin film piezoelectric MEMS vibration energy harvesters with two piezoelectric elements for higher output performance. Rev Sci Instrum. 2015;86(7).

10. Lin Z, Song J. Piezoelectric Nanogenerators Based on Zinc Oxide Nanowire Arrays. Science (80). 2016;312(5771):242-6.

11. Hindrichsen CG, Lou-Møller R, Hansen K, Thomsen E V. Advantages of PZT thick film for MEMS sensors. Sensors Actuators, A Phys. 2010;163(1):9-14.

12. Fang H Bin, Liu JQ, Xu ZY, Dong L, Wang L, Chen D, et al. Fabrication and performance of MEMS-based piezoelectric power generator for vibration energy harvesting. Microelectronics J. 2006;37(11):1280-4.

13. Kulkarni S, Roy S, O’Donnell T, Beeby S, Tudor J. Vibration based electromagnetic micropower generator on silicon. J Appl Phys. 2006;99(8):1-4.

14. Wang Q, Kuwano H, Cao ZP. Metal-based piezoelectric energy harvesters by direct deposition of PZT thick films on stainless steel. Micro Nano Lett. 2012;7(12):1158-61.

15. Tsujiura Y, Suwa E, Hida H, Suenaga K, Shibata K, Kanno I. Lead-free piezoelectric MEMS energy harvesters of stainless steel cantilevers. Proc Transducers \& Eurosensors XXVII: The 17h Int Conf on Solid-State Sensors, Actuators and Microsystems, Barcelona, 2013

16. Lin SC, Wu WJ. Piezoelectric micro energy harvesters based on stainless-steel substrates. Smart Mater Struct. 2013;22(4).

17. Takahashi T, Van Minh L, Umeda K, Fujii T, Kuwano H. Fabrication and characterization of micromachined piezoelectric energy harvesters exploiting flexible $\mathrm{Pb}(\mathrm{Nb}, \mathrm{Zr}, \mathrm{Ti}) \mathrm{O} 3 / \mathrm{SUS}$. J Phys Conf Ser. 2018;1052(1).

18. Tang WH, Lin TK, Chen CT, Fu YH, Lin SC, Wu WJ. A High Performance Piezoelectric Micro Energy Harvester Based on Stainless Steel Substrates. J Phys Conf Ser. 2018;1052(1).

19. Berdy DF, Srisungsitthisunti P, Jung B, Xu X, Rhoads JF, Peroulis D. Low-frequency meandering piezoelectric vibration energy harvester. IEEE Trans Ultrason Ferroelectr Freq Control. 2012;59(5):846-58.

20. Katsumura H, Konishi T, Okumura H, Fukui T, Katsu M, Terada T, et al. Development of Piezoelectric Vibration Energy Harvesters for Battery-Less Smart Shoes. J Phys Conf Ser. 2018;1052:12060. 
21. Colin M, Basrour S, Rufer L, Bantignies C, Nguyen-Dinh A. Highly efficient low-frequency energy harvester using bulk piezoelectric ceramics. J Phys Conf Ser. 2013;476(1).

22. Fernandes E, Martin B, Rua MI, Zarabi S, Debéda H, Nairn D, et al. Design, fabrication, and testing of a low frequency MEMS piezoelectromagnetic energy harvester. Smart Mater Struct. 2018;27(3).

23. Yang Z, Zarabi S, Fernandes E, Rua MI, Debéda H, Salehian A, et al. A Simple Wireless Sensor Node System for Electricity Monitoring Applications: Design, Integration, and Testing with Different Piezoelectric Energy Harvesters. Sensors. 2018;18(11):3733.

24. Lou-Moeller R, Hindrichsen CC, Thamdrup LH, Bove T, Ringgaard E, Pedersen AF, et al. Screenprinted piezoceramic thick films for miniaturised devices. J Electroceramics. 2007;19(4):333-8.

25. Xu R, Lei A, Dahl-Petersen C, Hansen K, Guizzetti M, Birkelund K, et al. Screen printed PZT/PZT thick film bimorph MEMS cantilever device for vibration energy harvesting. Sensors Actuators, A Phys. 2012;188:383-8.

26. Zang M, Polla DL, Zurn SM, Cui T. Stress and Deformation of Pzt Thin Film on Silicon Wafer Due to Thermal Expansion. MRS Proceedings. [Online] Cambridge University Press; 1999;574: 107. Available from: doi:10.1557/PROC-574-107

27. Hsueh $\mathrm{CH}$, Luttrell CR, Cui T. Thermal stress analyses of multilayered films on substrates and cantilever beams for micro sensors and actuators. J Micromechanics Microengineering. 2006;16:2509-15.

28. Debéda H, Lucat C, Pommier-Budinger V. Printed Piezoelectric Materials for Vibration-based Damage Detection. Procedia Eng. 2016;168:708-12.

29. IEEE Standards on Piezoelectric Crystals:Measurements of Pieozolelectric Ceramics- 1961. IEEE Std 179-1961 (ANSI C83.24-1962). 1961. p. 1-8.

30. Lucat C, Martin MP, Debéda-Hickel H, Largeteau A, Ménil F. Screen-printed varistors: New strategy for high non-linear coefficient. J Eur Ceram Soc. 2007;27(13-15):3883-6.

31. Debéda H, Clément P, Llobet E, Lucat C. One-step firing for electroded PZT thick films applied to MEMS. Smart Mater Struct. 2015;24(2).

32. Ravi D, Green DJ. Sintering stresses and distortion produced by density differences in bi-layer structures. J Eur Ceram Soc. 2006;26(1-2):17-25.

33. Molla T, Lund H. Modeling Macroscopic Shape Distortions during Sintering of Multi-layers. Technical University of Denmark; 2014.

34. Meggit Sensing Systems. Pz26 ( Navy I ) Hard relaxor type PZT [Online]. Vol. 26, Pz26 ( Navy I 
) Ferroperm. p. 4912-3. Available from: /www.meggittferroperm.com

35. Lakhmi R, Debeda H, Dufour I, Lucat C, Maglione M. Study of screen-printed PZT cantilevers both self-actuated and self-read-out. Int J Appl Ceram Technol. 2014;11(2):311-20.

36. Xu R, Kim S-G. Figures of Merits of Piezoelectric Materials in Energy. In: Power MEMS. Atlanta, GA, USA. 2012 p. 464-7.

\section{Figure captions}

Fig. 1. Design of EH multilayer cantilevers (a-d) : (a) zig-zag cantilever with laser micromachined SS substrate with a zoom on the printed Au and PZT layers, (b) bottom Au electrode, (c) PZT layer, and (d) top Au electrode. All dimensions are in $\mathrm{mm}$.

Fig. 2. Fabrication screen-printing steps of EH multi-layer (modified zig-zag and simple cantilever): (a) bottom Au electrode printing, (b) active PZT layer printing (c) top Au electrode printing, (d) cross section of cantilevers. Top view with Au/PZT/Au printed layers of (e) zig-zag EH, and (f) simple cantilever structure equivalent to the middle branch of zig-zag cantilever. Dimension in $\mathrm{mm}$.

Fig. 3. Schematic view of the screen-printed layers for the disks fabrication.

Fig. 4. Sintering cycle used for the densification of the different PZT based materials: ceramics, printed disks, cantilevers and zig-zag structure (sintering: $2 \mathrm{~h}$ at $900^{\circ} \mathrm{C}$ ).

Fig. 5. SEM images of PZT $+3 \%$ wt LBCu for (a) fracture section of ceramic, (b) printed cantilever cross polished section, and (c) fracture section of free-standing printed disk.

Fig. 6. (a) Modified zig-zag cantilever EH structure after firing, (b) with a PZT layer of $100 \mu \mathrm{m}$ thickness, (c) with a PZT layer of $55 \mu \mathrm{m}$ thickness.

Fig. 7. Thermal expansion coefficient curves of SS substrate (a), and PZT ceramic (b).

Fig. 8. Cross section of multilayer structure with coordinate system used in the analyze [32].

Fig. 9. Comparison between calculated absolute values using eq. 3 and the measured experimental values for the curvature of multilayer structure analysis

Fig. 10. SEM analysis of (a) Au/PZT/Au/SS, (b) top Au electrode/PZT interface and, (c) interface layer between bottom Au electrode and SS substrate.

Fig. 11. Energy Dispersive X-ray (EDX) analysis of SS/Au/PZT multilayer structure: chemical cartography of $\mathrm{Au} / \mathrm{SS}$ interface layer after sintering.

Fig. 12. Permittivity (a) and $\tan \delta$ (b) for PZT ceramic at different frequencies and as a function of temperature $\left(23<\mathrm{T}\left({ }^{\circ} \mathrm{C}\right)<450\right)$.

Fig. 13. Impedance measurements: Conductance $(G)$ and Susceptance (B) of (a) printed disk (b) and printed cantilever.

\section{Table captions}

Table 1. Elastic properties, average thermal expansion coefficient $\left(500^{\circ} \mathrm{C}-600^{\circ} \mathrm{C}\right)$ and thicknesses of PZT and SS.

Table 2. Summary of properties for the different PZT based structures. 


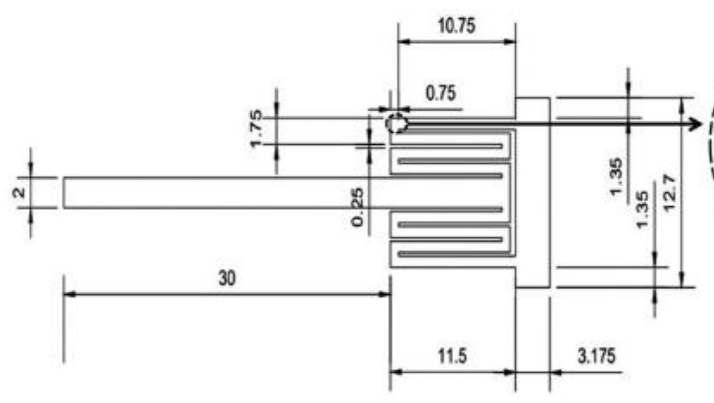

(A)

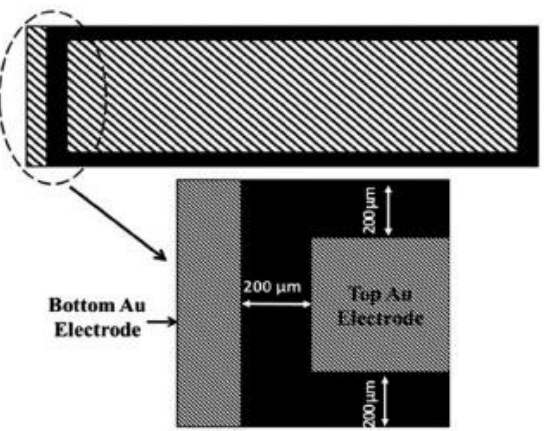

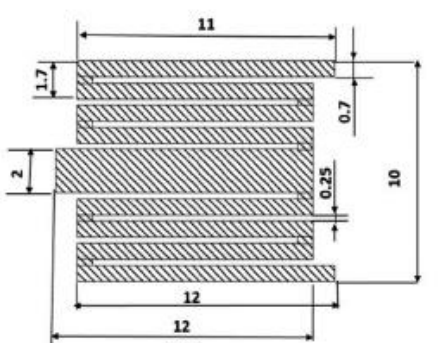

(B)

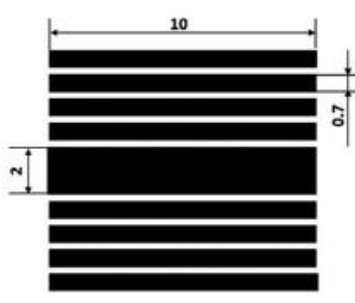

(C)

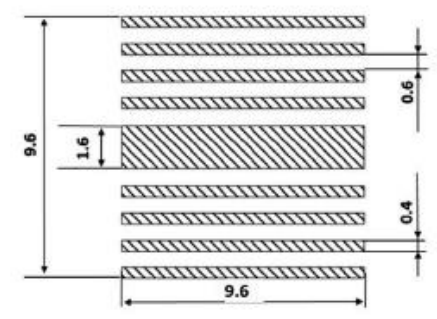

(D)

FIG U RE 1 Design of EH multilayer cantilevers (A-D): (A) zig-zag cantilever with laser micromachined SS substrate with a zoom on the printed Au and PZT layers, (B) bottom Au electrode, (C) PZT layer, and (D) top Au electrode. All dimensions are in mm

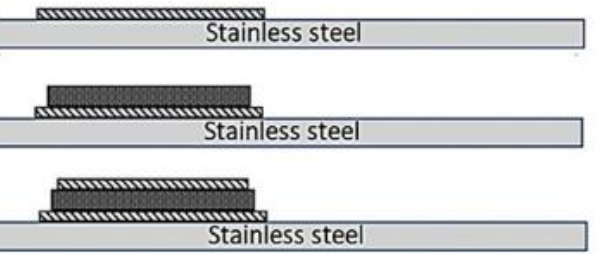

$\mathbb{M}_{\mathrm{Nu}} \square \mathrm{PZT}$
(A)

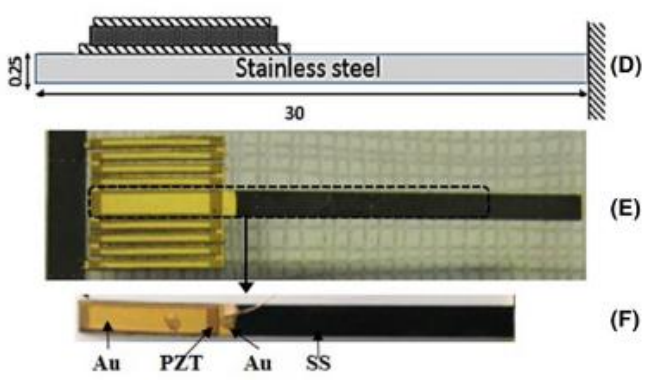

FIG U RE 2 Fabrication screen-printing steps of EH multi-layer (modified zig-zag and simple cantilever): (A) bottom Au electrode printing, (B) active PZT layer printing (C) top Au electrode printing, (D) cross section of cantilevers. Top view with Au/PZT/Au printed layers of (E) zigzag EH, and (F) simple cantilever structure equivalent to the middle branch of zig-zag cantilever. Dimension in mm [Color figure can be viewed at wileyonlinelibrary.com] 
DV Electrodes (Au)

Active layer (PZT)

Sacrificial layer (Polyester based)

Ceramic substrate (AIN)
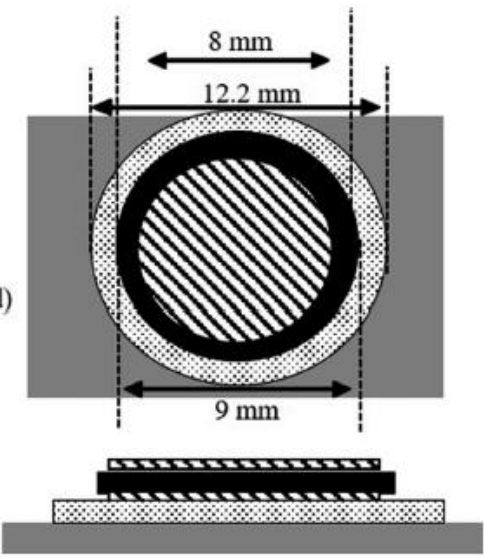

FIG URE 3 Schematic view of the screen-printed layers for the disks fabrication
FIG URE 4 Sintering cycle used for the densification of the different PZT based materials: ceramics, printed disks, cantilevers and zig-zag structure (sintering: 2 hours at $900^{\circ} \mathrm{C}$ )



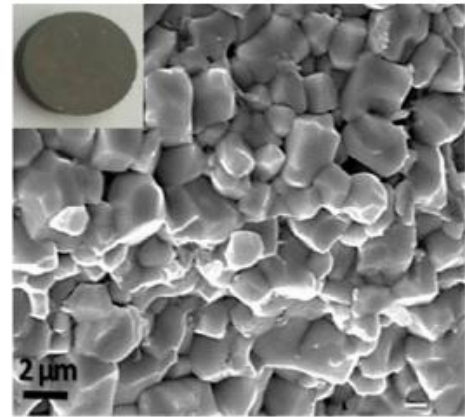

(A)

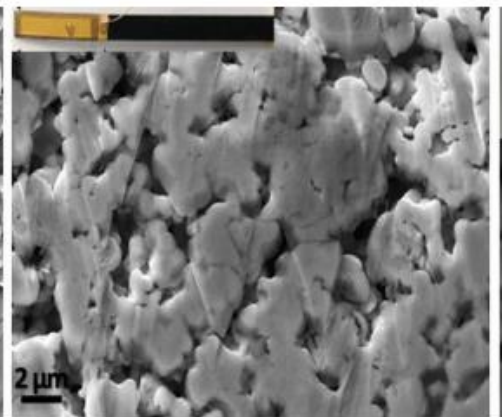

(B)

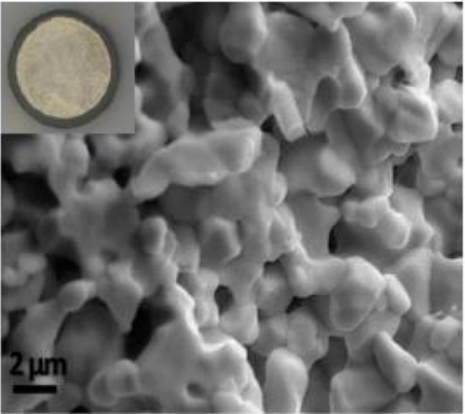

(C)

FIG U RE 5 SEM images of PZT + 3\% wt LBCu for (A) fracture section of ceramic, (B) printed cantilever cross polished section, and (C) fracture section of free-standing printed disk [Color figure can be viewed at wileyonlinelibrary.com] 

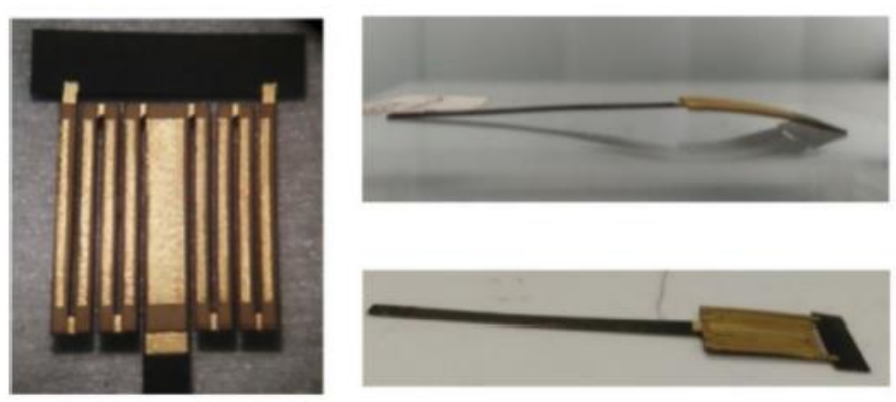

(A)
(B)

FIG URE 6 (A) Modified zig-zag

cantilever EH structure after firing, (B) with a PZT layer of $100 \mu \mathrm{m}$ thickness, (C) with a PZT layer of $55 \mu \mathrm{m}$ thickness [Color figure can be viewed at wileyonlinelibrary.com]

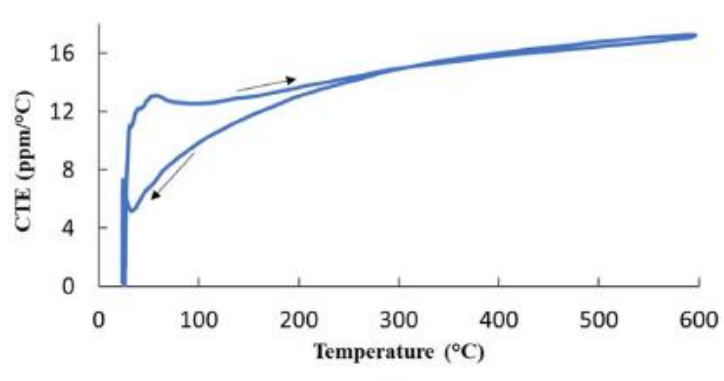

(A)

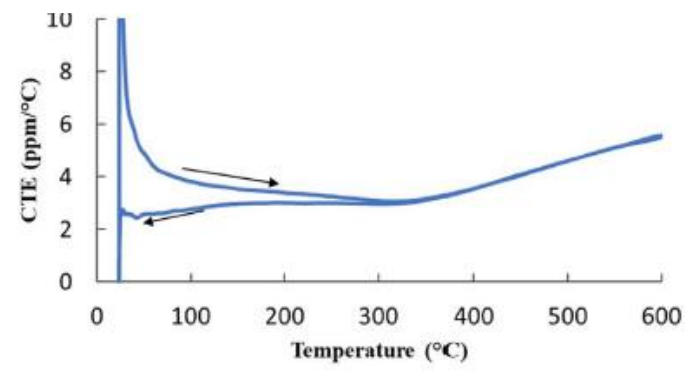

(B)

FIG U RE 7 Thermal expansion coefficient curves of SS substrate (A), and PZT ceramic (B) [Color figure can be viewed at wileyonlinelibrary. com]

FIG URE 8 Cross section of multilayer structure with coordinate system used in the analyze $^{27}$








F IG U RE 9 Comparison between calculated absolute values using Equation 3 and the measured experimental values for the curvature of multilayer structure analysis [Color figure can be viewed at wileyonlinelibrary.com]

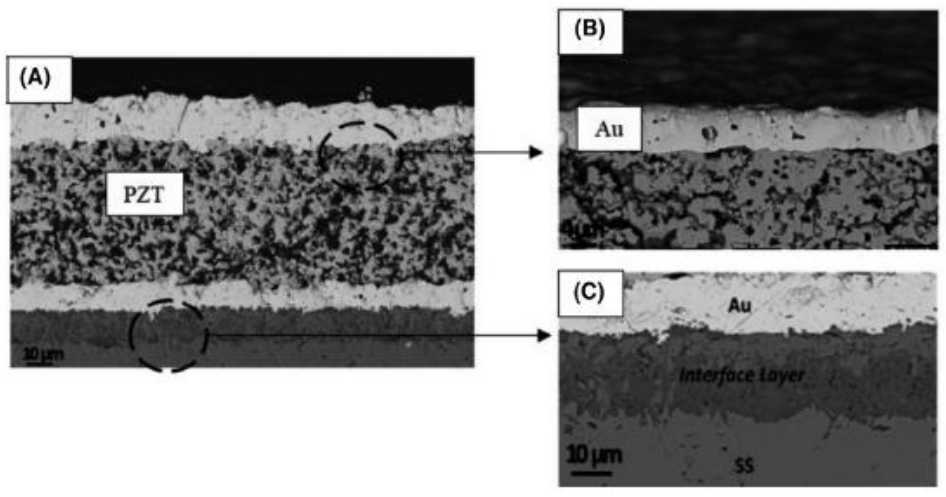

FIG URE 10 SEM analysis of (A) $\mathrm{Au} / \mathrm{PZT} / \mathrm{Au} / \mathrm{SS}$, (B) top Au electrode/PZ interface and, $(\mathrm{C})$ interface layer between bottom Au electrode and SS substrate 

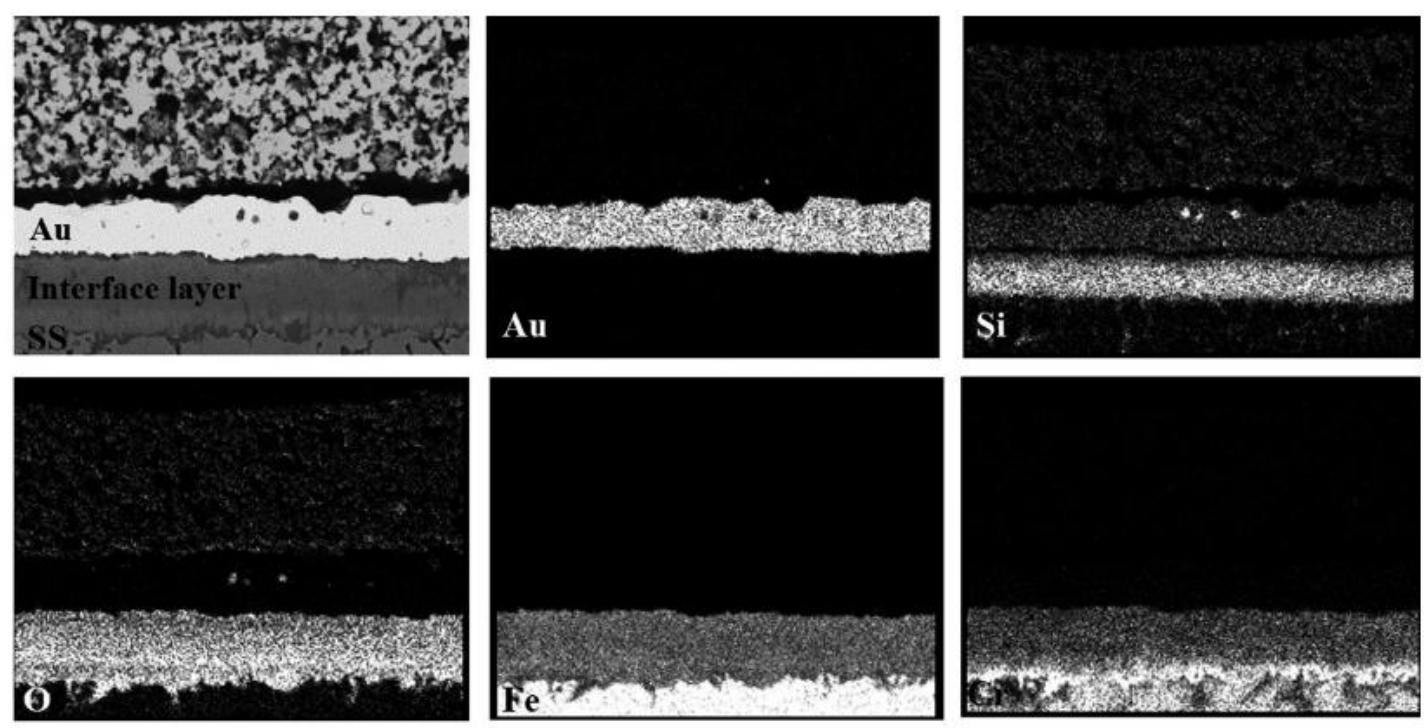

FIG U RE 11 Energy Dispersive X-ray (EDX) analysis of SS/Au/PZT multilayer structure: chemical cartography of Au/SS interface layer after sintering
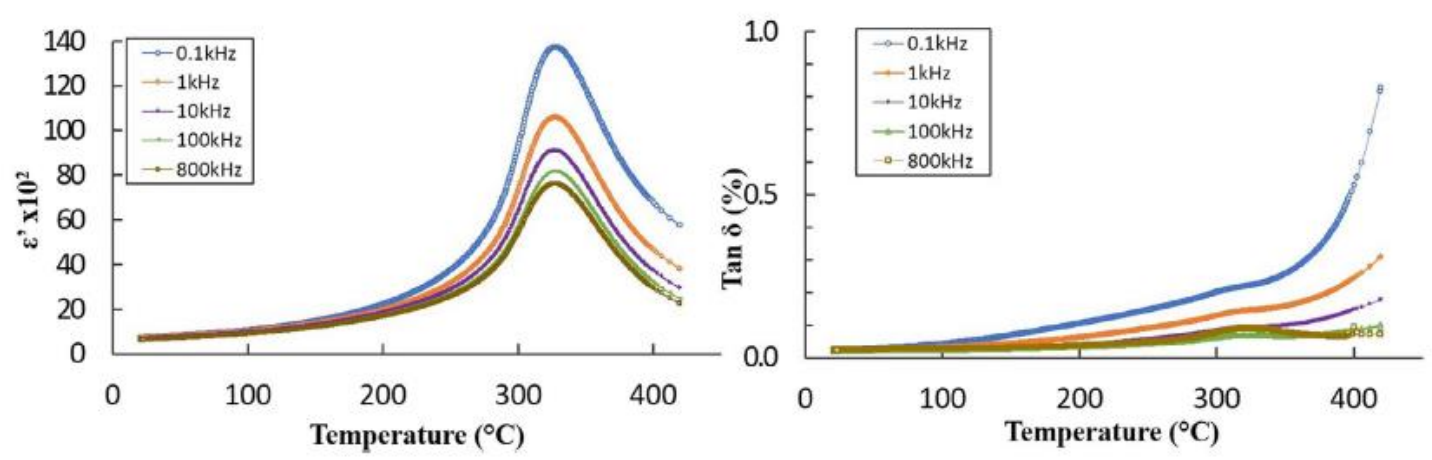

FIG URE 12 Permittivity (A) and $\tan \delta$ (B) for PZT ceramic at different frequencies and as a function of temperature $\left(23<T\left({ }^{\circ} \mathrm{C}\right)<450\right)$ [Color figure can be viewed at wileyonlinelibrary.com]
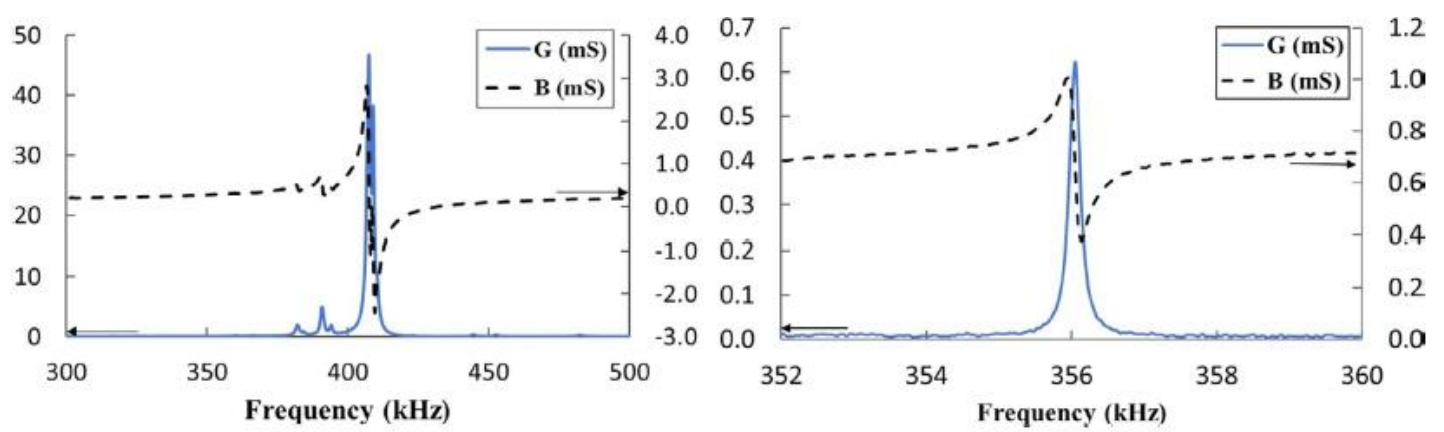

F IG U RE 13 Impedance measurements: Conductance (G) and Susceptance (B) of (a) printed disk (b) and printed cantilever [Color figure can be viewed at wileyonlinelibrary.com] 
TA BLE 1 Elastic properties, average thermal expansion coefficient $\left(500^{\circ} \mathrm{C}-600^{\circ} \mathrm{C}\right)$ and thicknesses of PZT and SS

\begin{tabular}{|ll}
\hline SS Young's Modulus $(\mathrm{GPa})$ & $193^{\mathrm{a}}$ \\
\hline PZT Young's Modulus $(\mathrm{GPa})$ & $40^{\mathrm{a}}$ \\
\hline SS Poisson's ratio & $0.24^{\mathrm{a}}$ \\
\hline PZT Poisson's ratio & $0.33^{\mathrm{b}}$ \\
\hline$\alpha_{\mathrm{SS}}\left(\mathrm{ppm} /{ }^{\circ} \mathrm{C}\right)$ & 16.7 \\
$\alpha_{\mathrm{PZT}}\left(\mathrm{ppm} /{ }^{\circ} \mathrm{C}\right)$ & 4.7 \\
$t_{\mathrm{SS}}(\mu \mathrm{m})$ & 254 \\
\hline$t_{\mathrm{PZT}}(\mu \mathrm{m})$ & $10-100$ \\
\hline
\end{tabular}

Reference [22].

${ }^{b}$ Reference [34].

TA B LE 2 Summary of properties for the different PZT based structures

\begin{tabular}{|c|c|c|c|c|c|c|c|}
\hline $\begin{array}{l}\text { Structure/ } \\
\text { properties }\end{array}$ & Ceramic & $\begin{array}{l}\text { Printed } \\
\text { disk }\end{array}$ & $\begin{array}{l}\text { Simple } \\
\text { cantilever } \\
\text { (PZT printed } \\
\text { on SS) }\end{array}$ & $\begin{array}{l}\text { Zig-zag EH } \\
\text { structure } \\
\text { Simulated } \\
\text { values }^{22}\end{array}$ & $\begin{array}{l}\text { PZ26 Ferroperm } \\
\text { (ceramic } \\
\text { pellets fired at } \\
1200^{\circ} \mathrm{C}-1300^{\circ} \mathrm{C} \text { ) }\end{array}$ & $\begin{array}{l}\text { Simple cantilever } \\
\text { with thinned bulk } \\
\text { ceramic PZT/SS } \\
15 \mu \mathrm{m} / \mathrm{PZT}^{21}\end{array}$ & $\begin{array}{l}\text { Simple } \\
\text { cantilever with } \\
\text { aerosol PZT/ } \\
\text { SS }^{16}\end{array}$ \\
\hline Density $\mathrm{kg} / \mathrm{m}^{3}$ & 7600 & 7400 & 6000 & 5500 & 7800 & -- & - \\
\hline $\begin{array}{l}\text { Dimensions } \\
(\mathrm{mm}): \\
\text { Diameter or } \\
\text { footprint }\end{array}$ & \&:11.45 & $\propto 7.74$ & $9.80 \times 2$ & $14.70 \times 12.70$ & - & $5 \times 40$ & $6 \times 4$ \\
\hline PZT thickness & 1.92 & 0.10 & 0.55 & 0.55 & -- & 0.10 & 0.01 \\
\hline $\begin{array}{l}\varepsilon^{\prime}(\text { at } 1 \mathrm{kHz}, \\
\left.25^{\circ} \mathrm{C}\right)\end{array}$ & 1200 & 600 & - & $630^{\mathrm{a}}$ & 1300 & - & - \\
\hline $\begin{array}{l}\tan \delta(\text { at } 1 \mathrm{kHz}) \\
(\%)\end{array}$ & -0.2 & -2.5 & - & $1.5^{\mathrm{a}}$ & 0.3 & - & - \\
\hline$k_{\text {eff }}(\%)$ & 28 & 26 & 11 & $15^{\mathrm{a}}$ & - & 23 & 10 \\
\hline$k_{p}(\%)$ & 64 & 73 & & & 57 & & \\
\hline$k_{3 l}(\%)$ & 37 & 42 & - & - & 33 & -- & - \\
\hline$-d_{3 l}(\mathrm{pC} / \mathrm{N})$ & 126 & 121 & - & $40^{\mathrm{a}}$ & 130 & -- & 17 \\
\hline
\end{tabular}

Note: --, Not reported.

${ }^{2} \mathrm{~V}$ alues used in simulation. 